\title{
Influence of anti-tumour necrosis factor therapy on cardiovascular risk factors in patients with active rheumatoid arthritis
}

\author{
C Popa, M G Netea, T Radstake, J W M Van der Meer, A F H Stalenhoef, \\ P L C M van Riel, P Barerra
} ..................................

Ann Rheum Dis 2005;64:303-305. doi: 10.1136/ard.2004.023119

Background: Tumour necrosis factor (TNF) is known to increase the concentrations of interleukin (IL) 6 and C reactive protein (CRP) and to induce proatherogenic changes in the lipid profile and may increase the cardiovascular risk of patients with rheumatoid arthritis (RA) and other inflammatory disorders.

Objective: To assess whether anti-TNF therapy modifies the cardiovascular risk profile in patients with RA.

Methods: The lipoprotein spectrum and the inflammation markers CRP and IL6 were investigated in 33 patients with RA treated with human anti-TNF monoclonal antibodies (D2E7, adalimumab, Humira) and 13 patients with RA given placebo, before and after 2 weeks' treatment.

Results: In the anti-TNF treated group, the mean (SD) concentrations of $\mathrm{HDL}$-cholesterol were significantly higher after 2 weeks' treatment $(0.86 \quad(0.30) \mathrm{mmol} / \mathrm{I} v 0.98$ (0.33) $\mathrm{mmol} / \mathrm{I}, \mathrm{p}<0.01$ ), whereas $\mathrm{LDL}$ and triglyceride levels were not significantly changed. Additionally, a significant decrease in CRP (86.1 (54.4) mg/l v 35.4 (35.0) mg/l, $\mathrm{p}<0.0001)$, and IL6 (88.3 (60.5) pg/ml v 42.3 (40.7) pg/ $\mathrm{ml}, \mathrm{p}<0.001)$ concentrations was seen in this group. No changes in lipid profile, IL6, or CRP levels were seen in the placebo group.

Conclusions: TNF neutralisation with monoclonal anti-TNF antibodies increased HDL-cholesterol levels and decreased CRP and IL6 levels after 2 weeks. Therefore this treatment may improve the cardiovascular risk profile of patients with RA.

$\mathrm{D}$ uring the inflammatory response, multiple alterations of the intermediary lipid metabolism occur. These encompass hypertriglyceridaemia and decreased high density lipoprotein (HDL) cholesterol levels and low density lipoprotein (LDL) cholesterol levels. ${ }^{1}$ Despite the decrease in LDL-cholesterol, the levels of small dense LDL, a particle believed to be proatherogenic, increase during inflammation. ${ }^{1}$ Thus, the pattern of lipid metabolism during inflammation is proatherogenic, and is believed to contribute to atherosclerosis, especially in chronic inflammatory diseases such as rheumatoid arthritis (RA). ${ }^{1}$ Tumour necrosis factor $\alpha$ (TNF $\alpha$ ) is a proinflammatory cytokine with pronounced effects on lipoprotein metabolism, ${ }^{2}$ and this cytokine has a major role in the pathogenesis of RA.

Patients with untreated active RA have altered lipoprotein and apolipoprotein patterns that may increase the risk of atherosclerosis. ${ }^{3}$ This is supported by studies showing that mortality among patients with RA is increased, predominantly owing to cardio- and cerebrovascular diseases. ${ }^{4}$
Moreover, carotid artery intima media thickness, as measured by ultrasound, is increased in patients with RA, suggesting a greater prevalence of subclinical atherosclerosis. ${ }^{5}$ In addition, $\mathrm{C}$ reactive protein (CRP) and interleukin (IL) 6 levels are both raised in patients with active RA, and these acute phase reactants have recently been shown to be associated with cardiovascular risk. ${ }^{6}$ In patients with RA, treatment with antifolates was shown to raise homocysteine levels, which was also characterised as an independent risk factor for developing cardiovascular disease.

Therapeutic strategies, aimed at TNF neutralisation with monoclonal antibodies or TNF receptor fusion proteins, have been shown to reduce disease activity and structural damage and to improve the quality of life in patients with RA. ${ }^{8}$ Moreover, blocking TNF results in a rapid decrease of acute phase reactants. ${ }^{9}$ Given these facts, we asked the question whether anti-TNF treatment would also change the cardiovascular risk profile. To this aim, we assessed the lipid profile and acute reaction markers before and 2 weeks after the first dose of anti-TNF or placebo in patients with active RA enrolled in monotherapy trials with a fully human anti-TNF monoclonal antibody (D2E7, adalimumab, Humira; Abbott Laboratories) at our centre.

\section{PATIENTS AND METHODS \\ Patients}

Patients with active RA included in phase I, double blind clinical studies with adalimumab monotherapy at our centre were studied. Patients fulfilled the 1987 American College of Rheumatology criteria, had an active disease as defined by a Disease Activity Score (DAS) $>3.2$ at baseline, and underwent a washout period for disease modifying antirheumatic drugs of at least 3 weeks before the start of the study. Stable doses of non-steroidal anti-inflammatory drugs and prednisone ( $<10 \mathrm{mg} /$ day) were allowed during the study. Measurements of the variables studied were made on blood samples collected before the administration of an anti-TNF dose, at baseline and 2 weeks after starting treatment.

\section{Methods}

Fasting blood samples were collected in vacutainer tubes (Beckton \& Dickinson, Rutherford, NJ) containing K3-EDTA ( $1 \mathrm{mg} / \mathrm{ml}$ ), centrifuged at $3600 \mathrm{rpm}$ for 8 minutes at $4^{\circ} \mathrm{C}$, supplemented with saccharose as a cryoprotectant (final concentration $6 \mathrm{mg} / \mathrm{ml}$ ), and frozen at $-80^{\circ} \mathrm{C}$ until assay. Cholesterol and triglyceride (TG) were determined by commercially available enzymatic reagents on the Hitachi

Abbreviations: CRP, C reactive protein; DAS, Disease Activity Score; HDL, high density lipoprotein; IL, interleukin; LDL, low density lipoprotein; RA, rheumatoid arthritis; TG, triglyceride; TNF $\alpha$, tumour necrosis factor $\alpha$ 

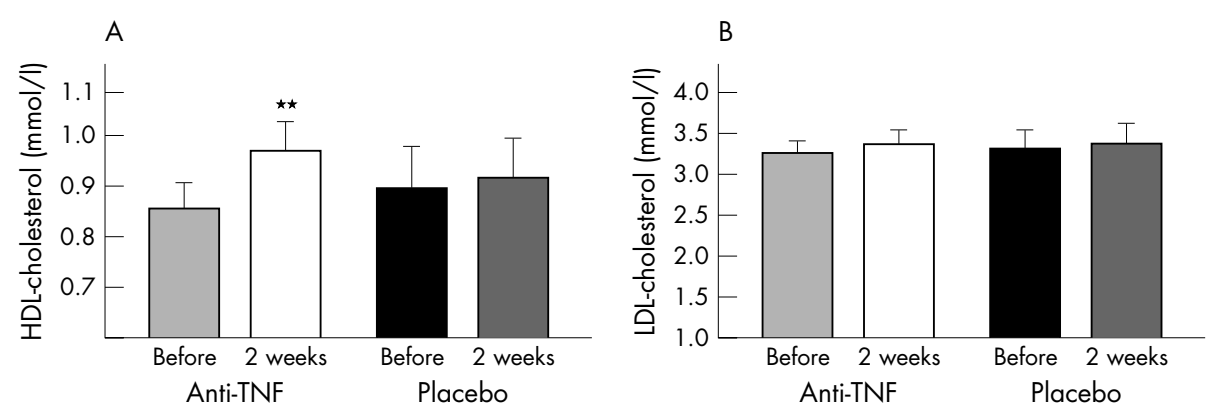

Figure 1 Concentrations of HDL-cholesterol (A) and LDL-cholesterol (B) in 33 patients with RA before and 2 weeks after treatment with a fully human anti-TNF monoclonal antibody or with placebo. ${ }^{* *} \mathrm{p}<0.0001$.

747 analyser (Boehringer Mannheim, Germany), while HDLcholesterol was determined by the phosphotungstate $/ \mathrm{Mg}^{2+}$ method. ${ }^{10}$ LDL-cholesterol was calculated with the Friedewald formula, which provides reliable values up to a TG concentration of $8.0 \mathrm{mmol} / \mathrm{l}$. IL6 was determined by a commercial enzyme linked immunosorbent assay (ELISA; BioSource Etten-Leur, The Netherlands), according to the manufacturer's instructions.

CRP was measured by immunoturbidometry with the Hitachi 747 analyser using reagents from Roche (Nos 1776371 and 1776428) and the calibrator BCDl. Sensitivity level was $1 \mathrm{mg} / \mathrm{l}$ and the coefficient of variation was $<2 \%$.

\section{Statistical analysis}

Within group comparisons were made using the Wilcoxon signed rank test (for IL6 and TG) and the paired Student's $t$ test (for CRP, HDL, LDL, and total cholesterol). Significance was set at the 0.05 level. Values are expressed as mean (SD).

\section{RESULTS}

Within 2 weeks of anti-TNF administration a $6 \%$ increase in total cholesterol concentrations was observed (4.70 (1.08) $\mathrm{mmol} / \mathrm{l} v 5.02(1.16) \mathrm{mmol} / \mathrm{l}, \mathrm{p}=0.001)$. This was mainly explained by an increase in the HDL-cholesterol concentrations (mean of $15 \%$, from $0.86(0.30) \mathrm{mmol} / \mathrm{l}$ to $0.98(0.33) \mathrm{mmol} / \mathrm{l}, \mathrm{p}<0.0001)$ (fig $\mathrm{lA}$ ). In contrast, LDLcholesterol and TG measurements were not significantly changed (3.26 (0.88) mmol/l v 3.37 (1.02) mmol/l, mean 3\%; fig $\mathrm{lB}$, and $1.46(0.60) \mathrm{mmol} / \mathrm{l} \quad v \quad 1.38 \quad(0.73) \mathrm{mmol} / \mathrm{l}$, respectively). The LDL:HDL ratio and the total cholesterol:HDL ratio, significantly decreased in the antiTNF treated group compared with placebo treated patients (4.01 (1.85) v 4.36 (2.16), $\mathrm{p}=0.017$, and 5.76 (2.42) $\vee 6.24$ (2.69), $\mathrm{p}=0.004$, respectively). The concentrations of total cholesterol, HDL-cholesterol, LDL-cholesterol, and TGs, as well as the LDL:HDL and total cholesterol:HDL ratios, did not change after placebo administration. Figure 2 shows that the levels of CRP and IL6 decreased significantly within 2 weeks of anti-TNF administration $(\mathrm{p}<0.0001$ and $\mathrm{p}<0.001$ for CRP and IL6, respectively), whereas no changes were observed after placebo.

Clinical improvement occurred rapidly after initiation of anti-TNF therapy but not after placebo. This was reflected by a decrease in the DAS in the treated group and a stable DAS in the placebo group $(5.24$ (1.05) to $4.06(1.14)$ and 4.8 (1.13) to 4.96 (1.4), respectively).

\section{DISCUSSION}

In this study we show that TNF $\alpha$ neutralisation with anti$\mathrm{TNF} \alpha$ monoclonal antibodies in patients with active RA significantly increases the total cholesterol, mainly owing to enhanced HDL-cholesterol concentrations already within 2 weeks of treatment. In contrast, there were no significant changes in the LDL-cholesterol and triglyceride concentrations, and the LDL:HDL ratio significantly decreased. These changes are concomitant with a significant decrease in the disease activity and acute phase reactants CRP and IL6. We therefore suggest that if these rapid changes in lipid pattern are maintained, this may also result in a decreased cardiovascular risk in patients with chronic inflammatory disorders.

It is well known that TNF $\alpha$ induces hypertriglyceridaemia in animals and humans. ${ }^{211}$ This is due to an increased de novo fatty acid synthesis in the liver and esterification to form TGs, to induction of lipolysis in adipose tissue, and to decreased lipoprotein lipase activity. ${ }^{2}$ From this perspective, one would expect a decrease in TG concentrations after antiTNF therapy, though this was not the case in our study. This might be explained by the short follow up period or, alternatively, by the lower but still persistent inflammation at week 2.

Besides TNF $\alpha$, other cytokines, including ILl $\beta$, IL6, and interferon $\gamma$, can modulate the lipid metabolism. ${ }^{2}$ TNF is a major inducer of these cytokines and TNF neutralisation may
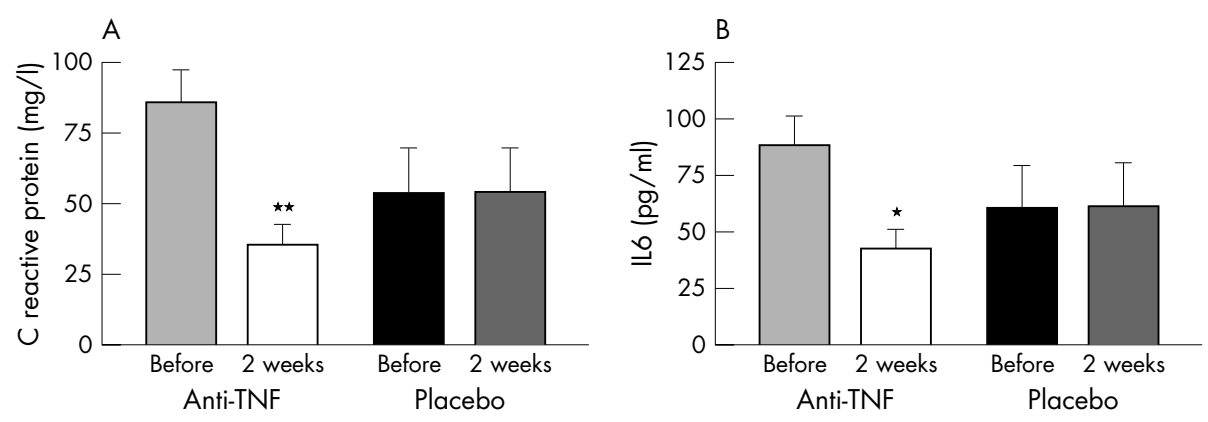

Figure 2 CRP (A) and IL6 (B) concentrations in 33 patients with RA treated with anti-TNF monoclonal human antibodies and with placebo, before and after 2 weeks' treatment. ${ }^{*} \mathrm{p}<0.001 ;{ }^{* *} \mathrm{p}<0.0001$. 
result in a decrease of the above-mentioned cytokines. Therefore, possibly, the positive effect of TNF $\alpha$ blockade on the lipid profile is also mediated by the inhibition of other cytokines.

Before our study two other small studies had assessed the effect of TNF neutralisation with the chimeric monoclonal antibody infliximab on lipoproteins in patients with rheumatic diseases. Hurlimann et al also found a slight increase in total cholesterol in 11 patients treated for 12 weeks, but no data were provided about HDL, LDL, and TGs. ${ }^{12}$ In another study, Cauza et al found an increase in TGs and a decrease in HDL concentrations in seven patients with RA after an average of 3 weeks' treatment. ${ }^{13}$ The discrepancies between the latter study and ours may be explained by the small number of patients tested by Cauza.

In patients with active RA, IL6 and CRP concentrations are increased and this is most probably mediated by the action of TNF $\alpha$. The effect of anti-TNF therapy on the levels of acute phase reactants observed in this study is similar to the effect previously described. ${ }^{912}$ IL6 and CRP, as markers of inflammation, have recently been shown to be positively associated with the cardiovascular risk. ${ }^{6}$ In the general population, CRP levels much lower than those found in RA are already associated with an increased cardiovascular risk. It is tempting to speculate that the decreased CRP, as a mirror of inflammatory status, leads to a decreased risk for atherosclerosis and cardiovascular events in patients with RA treated with TNF blocking agents, as an association between anti-inflammatory treatment and cardiovascular comorbidity was also previously seen in these patients. ${ }^{14}$

In conclusion, we would like to propose that anti-TNF treatment through both improving the lipid pattern (higher HDL-cholesterol and decreased LDL:HDL ratio) and decreasing inflammation, improves the cardiovascular risk profile of patients with RA. This is strongly supported by a recent study in a large cohort of patients with RA, where anti-TNF therapy was associated with a decreased incidence of cardiovascular events. ${ }^{15}$ Moreover, we are currently testing this hypothesis in our clinic in larger cohorts of patients, with a longer follow up and using objective measurements of the atherosclerotic process.

\section{ACKNOWLEDGEMENT}

Dr Calin Popa was partly supported by a grant from EULAR.

\section{Authors' affiliations}

C Popa, T Radstake, P L C M van Riel, P Barerra, Department of Rheumatology, University Medical Centre St Radboud, Nijmegen, The Netherlands
C Popa, M G Netea, J W M Van der Meer, A F H Stalenhoef, Department of Internal Medicine, University Medical Centre St Radboud, Nijmegen, The Netherlands

Correspondence to: Dr P Barrera, Rheumatology Department, UMC St Radboud, Geert Grooteplein 8, PO Box 91016500 HB Nijmegen, The Netherlands; P.Barrera@reuma.umcn.nl

Accepted 1 June 2004

Published Online First 1 July 2004

\section{REFERENCES}

1 Khovidhunkit W, Memon RA, Feingold KR, Grunfeld C. Infection and inflammation-induced proatherogenic changes of lipoproteins. J Infect Dis 2000; 181(suppl 3):S462-72.

2 Grunfeld C, Feingold KR. Tumour necrosis factor, cytokines and the hyperlipidemia of infection. Trends in Endocrinology and Metabolism 1991;6:213-19.

3 Kinosian B, Glick H, Garland G. Cholesterol and coronary heart disease: predicting risks by levels and ratios. Ann Intern Med 1994;121:641-7.

4 Van Doornum S, McColl G, Wicks IP. Accelerated atherosclerosis: an extraarticular feature of rheumatoid arthritis? Arthritis Rheum 2002;46:862-73.

5 Park YB, Ahn CW, Choi HK, Lee SH, In BH, Lee HC, et al. Atherosclerosis in rheumatoid arthritis: morphologic evidence obtained by carotid ultrasound. Arthritis Rheum 2002;46:1714-19.

6 Ridker PM. Clinical application of C-reactive protein for cardiovascular disease detection and prevention. Circulation 2003;107:363-9.

7 van Ede $A E$, Laan RF, Blom HJ, Boers GH, Haagsma CJ, Thomas $C M$, et al. Homocysteine and folate status in methotrexate-treated patients with rheumatoid arthritis. Rheumatology (Oxford) 2002;41:658-65.

8 Lipsky PE, van der Heijde DM, St Clair EW, Furst DE, Breedveld FC, Kalden JR, et al. Infliximab and methotrexate in the treatment of rheumatoid arthritis. Anti-Tumor Necrosis Factor Trial in Rheumatoid Arthritis with Concomitant Therapy Study Group. N Engl J Med 2000;343:1594-602.

9 Barrera P, van Der Maas A, van Ede AE, Kiemeney BA, Laan RF, van de Putte $L B$, et al. Drug survival, efficacy and toxicity of monotherapy with a fully human anti-tumor necrosis factor-alpha antibody compared with methotrexate in long-standing rheumatoid arthritis. Rheumatology (Oxford) 2002;41:430-9.

10 Demacker PNM, Hessels M, Toenhaake-Dijkstra $\mathrm{H}$, Baadenhuijsen $\mathrm{H}$. Precipitation methods for high-density lipoprotein cholesterol measurement compared, and final evaluation under routine operating conditions of a method with a low sample to reagent ratio. Clin Chem 1997;43:663-8.

11 Sherman ML, Spriggs DR, Arthur KA, Imamura K, Frei E 3rd, Kufe DW. ecombinant human tumor necrosis factor administered as a five-day continous infusion in cancer patients: phase I toxicity and effects on lipid metabolism. $J$ Clin Oncol 1988;6:344-50.

12 Hurlimann D, Forster A, Noll G, Enseleit F, Chenevard R, Distler O, et al. Antitumour necrosis factor- $\alpha$ treatment improves endothelial function in patients with rheumatoid arthritis. Circulation 2002;106:2184-7.

13 Cauza E, Cauza K, Hanusch-Enserer U, Etemad M, Dunky A, Kostner K. Intravenous anti-TNF- $\alpha$ antibody therapy leads to elevated triglyceride and reduced $\mathrm{HDL}$-cholesterol levels in patients with rheumatoid and psoriatic arthritis. Wien Klin Wochenschr 2002;114:1004-7.

14 Choi HK, Hernan MA, Seeger JD, Robins JM, Wolfe F. Methotrexate and mortality in patients with rheumatoid arthritis: a prospective study. Lancet 2002;359:1173-7

15 Jacobsson LTH, Turesson C, Gulfe A, Crncik M, Petersson IF, Saxne T, et al. Low incidence of first cardiovascular event in rheumatoid arthritis patients treated with TNF-blockers [abstract]. Arthritis Rheum 2003;48:S241. 